ARTICLE

\title{
Journalistic Blogs in China: Political Dissent and the Formation of a Public Sphere
}

\author{
HAI TANG, UNIVERSITY OF SUSSEX
}

\begin{abstract}
There is considerable interest among scholars, professional journalists and columnists in practices at the edge of journalism, where the struggles for alternative modes of knowing become visible. In recent years, the commentary on and contribution to news stories in a larger number of personal blogs have potentially revolutionized journalism. In particular, some argue that journalists' blogs reconfigure politics around people's everyday lives, increasing the realm in terms of freedom speech and public participation.
\end{abstract}

To tap into such arguments, then, this paper uses the case of Lian Yue, a Chinese journalist, who wrote about a well-known public affair - Xiamen PX Project, from March to December in 2007 in his blog Lian Yue de Diba Dazhou (Lian Yue's Eighth Continent), that draws on the blogosphere as a comparative democratic public space in which the interaction between bloggers and active publics greatly encouraged public opinion to be freely expressed and had a crucial impact on decision making. Lian Yue's series of blogging on the Xiamen event presented a radical practice of news report that challenged the legitimacy of traditional sense of journalism in China. It is also indicative of one way in which journalism is changing, under pressure from Chinese reformers who are aware of new cultural, social and political contexts.

\section{KEYWORDS}

China; Xiamen PX Project; Blogging; News Transparency; Journalistic Blog.

\section{INTRODUCTION}

As economic reform in China deepens, Chinese journalism has undergone great changes since the reform and opening up policy in the late 1970s. On the one hand, media commercialization has potentially weakened political control and brought about certain degree of editorial autonomy (Zhang, 1993, p.209-210). On the other hand, the need for interactivity between media reporters and active audiences encourages media organizations to support aggressive journalists for their good stories (Ma, 2000, p.22-3). These have offered Chinese journalists opportunities to develop their professional discourse to interpret, justify and reconfigure the institutional space of their daily practices (Pan, 2000, p.274). However, efforts of media reform for a transparency in news dissemination have not yet completely satisfied Chinese radical journalists. Neither the previous example of reporting on SARS, nor the series television program of Jiaodian Fangtan (Focus) successfully acted in the way they 
were expected to. The former was in a crisis of following completely the central government's strict guidelines to preserve social and political stability (Tai and Sun, 2007), while the latter, as Yang Yuerong (2007, p.97) argues, is an image example of the party's wish to produce a program that can be regarded as democratic in form to achieve greater propaganda effectiveness. The dissatisfaction for Chinese journalists falls into a mainstream category. The state, to paraphrase Joseph Chan (2003), still expects its long-term propagandist piper to play its tune of a controller.

However, media censorship has exhibited extreme forms of variations and discrepancies. Eric Ma mentions that party newspapers at the central, provincial levels are intensively watched, while local papers, evening papers and cultural journals in coastal cities have gained much larger degree of freedom. Ma also points out that electronic media are more loosely censored than print media (Ma, 2000, p.23-4). The development and expansion of the Internet in China, for instance, have contributed to an increase in both news report and information access (Zheng and Wu, 2005; Massey and Luo, 2005). More investigative reporting and environmental issues have been concerned in newsroom (Tong, 2007). Added to these is the rise of the blog, along with instant messages and radical forums has particularly given Chinese journalists an online public space for the free flow of information. The blogosphere in China poses a challenge to independent online journalists (Massey and Luo, 2005) by facilitating alternative practice of news dissemination. Journalistic blogs are evaluated as not only a mode of news presentation, but also a special model of public journalism.

How do Chinese journalists use the blog and how do they perceive their professional utilities of the blogosphere? This paper draws attention on these questions, with the purpose of elaborating the political function of journalist blogs. As such, the main argument in this paper is twofold. Firstly, the crucial personal role played by journalistic bloggers has transformed Chinese news culture towards critical journalism (Pugsley and Gao, 2007, p.457; Zhao, 2006). Secondly, the popularity of journalistic blogs in China has created a new type of influence.

This paper proceeds in the following way. The first section provides a general background of the online public spheres in conflict with media censorship and sets forth a framework. The second section explores how the blogosphere is able to provide news information sources so that a new form of online journalism is developing in China. The third section uses Lian Yue de Diba Dazhou (Lian Yue's Eighth Continent) to illustrate how the blogosphere encourages civic engagement and political participation, and particularly, how news blogs can succeed in changing political and journalistic practices.

\section{ONLINE PUBLIC SPHERES IN STRUGGLE WITH MEDIA CENSORSHIP IN CHINA}

Habermas' concept of the public sphere is intended to elucidate the spaces where public voices and public discussions are directed to the world of politics (Calhoun, 1992, p.1; Zaret, 1992, p. 225-6). In his earlier view of public life, ruling elites that have direct hands in running the state are not the sort of the public that Habermas has in his mind. Rather, as Negt and Kluge argue, professionals such as politicians, editors and union officials (1993, p.2), or as Leon Mayhew (1997, p.143) suggests, intellectuals within universities and research institutes, were examples of potential bases for the specific publics that Habermas envisions. 
Habermas' model of public spheres emerged in the seventeen through mid twentieth centuries and focused upon a bourgeois class (Calhoun, 1992, p.1), and as long as discussions were opened by the bourgeois then these groups were presumed as representatives of the general public (Mayhew, 1997, p.143) for public welfare. For instance, Habermas points out:

\begin{abstract}
The process in which the state-governed public sphere was appropriated by the public of private people making use of their reason and was established as a sphere of criticism of public authority was one of functionally converting the public sphere in the world of letters already equipped with institutions of the public and with forum for discussion. $(1989$, p.51)
\end{abstract}

Here, Habermas implicitly mentioned that the public space was created by eighteenth century British journalism for impinging on the political system. However Habermas was criticized for his earlier bourgeois public spheres, for they were composed of a narrow sense of the European educated and propertied men, and they dominated a discourse power 'not only exclusive of others but prejudicial to the interests of those excluded' (Calhoun, 1992, p.3). As Alan McKee argues, 'It's necessary now for educated men to know what working-class audiences are debating, because it might affect legislation that will then apply to them' (2005, p.143). As a result, scholars have offered second opinions on the public sphere. They have turned largely, not only to focus on its continual expansion of participants, but also revealed an ongoing cultural and political significance. On the one hand, the public sphere opened up a comparative less controlled communicative space, in which diverse human interests were mutually shared (McGuigan, 1996, p.177). On the other hand, the public sphere encouraged critical measures of democratic communication.

The critical measures for improved and effective discourse are particularly embodied in the rise of the Internet-based communications. The Internet has indeed constituted an online public space for free discussions in many ways such as bulletin boards and MUDs (Multiuser domains). Howard Rheingold (2000) highlights that dialogues through the Internet invoke new version of the public sphere in terms of extending interactive capacities and creating democratic communications. As Jim McGuigan mentions:

The Net has, to a degree, proven up to be a cheap and convenient means for circumventing the restrictions of mainstream communications media. (1996, p.182)

Taking China as an example, a popular newspaper Yangcheng Wanbo (Yangcheng Evening Paper) in Southern China, its online version Jingyang Wang (Jingyang Net, http://www.ycwb.com.cn) attracts 400,000 readers per month due to it provides lots of information and it links to access some Western media, according to He Zhou and Zhu Jiahua (2002). Qianguo Luntan (the Strong Nation Forum) in the People's Net, a website managed by People's Daily, as Zheng Yongnian and Wu Guoguang (2005) exemplify, is much more liberal in content than the People's Daily, as more liberal political discussions are allowed in its electronic forum than in its parent newspaper. Yang Guobing (2003) discusses different types of online public spaces in China - portal sites, news groups, online magazines and bulletin boards, and he then notes that the four forums contain many more critical remarks about China policies as well as social and political issues.

However, the comparative liberal online spaces are not in a sense of indication that the Internet-based media can enjoy the kind of press freedom enjoyed in the West. In China, the government is indeed highly vigilant on the users' efforts to access different online sources of information. Pan Zhongdang introduces a general background of China media system: 
China's party-press system is built upon the idea that the media is an instrument by which the party propagates its policy and ideology. A set of practices has long been accepted as journalistic routines. These include: the state subsidizes the media; party committees at various levels of the communist hierarchy oversee the media at their respective levels by appointing key personnel, deciding major topics for news coverage, and censoring journalists' work; the party's Propaganda Ministry controls media content; journalism education trains 'party propagandists'. (2000, p.256)

Also, as Chen Huailin and Joseph Chan note:

The current effort to control the media is sustained and systematic. Also, a mixture of restrictive measures, including legal limitation, policy directives, administrative rules, mini campaigns and normative guidelines, are used. (1998, p.656)

As a consequence, in the process of Internet development, much attention has been paid to political control by administrative means and measures. For instance, the government has set up a series of rules such as censoring Internet content, governing online sites and regulating netizens, as Zheng Yongnian and Wu Guoguang (2005, p. 517) indicate, so as to minimize the 'harmful' effects of the Internet usage on the regime in China.

The Chinese government has particularly tightened news sites management. Radical sites such as Sixiang de Jingjie (Field of Thoughts), which provided a liberal academic discussion space, and Xinwenming Luntan (New Civilization Forum), in which critical ideas on democracy were inspired, had been frequently taken down. Not only domestic news sites, international papers were also filtered or blocked (Zittrain and Edelman, 2003) by the Chinese government, including, The Washington Post, The New York Times and publications based in Hong Kong in accordance to the nation's political needs. A well-known Chinese blogger Wang Xiaofeng, who officially works as an editor in Lifeweek magazine in Beijing, complained of China's Journalist's Day on his 'Anmo $R u$ ' (Massage Milk) (http://lydon.ycool.com):

I have always been ashamed of being a journalist in China... Before becoming a journalist, I had many dreams such as becoming a journalist with a conscience. Damn! After becoming the journalist, I found that we either lose our conscience, or we lose our self-confidence... Once I was talking to my boss, who has lots of money, and I tried to persuade him to invest in media industry. He said that the investing would be risky, because the print media are not allowed to report on this and on that...I suddenly felt that being a journalist in China is meaningless and boring... Journalists, do we still deserve celebrating our Journalist's Day?... It's more like having 'Journalist's Disaster' than celebrating a holiday.

(9 November 2005)

Wang's disappointment in terms of being an official Chinese journalist implicitly show that journalism reform should be carried out before a substantial structural change in the whole media system. While the first half of the 2000s has witnessed dramatic development of communication technology in China, particularly the rapid development of the Internet and mobile phone service, as active and rich sites of news delivery within individual media outlets (Huang, 2007). Added to these is that, the pervasive spread of blogs and the active blogosphere outside of the direct political control. This in turn can show something of how online journalism is developing in China. 


\section{NEWS BLOGS AND ONLINE JOURNALISM IN CHINA}

Blogging in China is growing every year. When the blog was first introduced into China in 2002, bloggers numbered fewer than 10,000 (Xie, 2007, p. 30). However, by the end of June 2009 users with a blog space have reached 300 million accounting for more than 40 percent of the total netizens in China (CNNIC, 2009). The surge of attention to blogs has triggered the democratic potential of the blogosphere in terms of its unprecedented opportunities for public discourse and political engagement. According to the Annual Blue Book on Social Development, published by the Chinese Academy of Social Sciences in January 2008, over 50 million blog readers consider the blogosphere as an important channel for the people of China to air their opinions on important affairs (CASS, 2008). Individuals are empowered by blogs to post any kinds of messages such as Muzi Mei's sexual diaries, Xiamen anti-PX movement and online citizen expressions on the 2008 Olympics, etc. Thus, blogs reshape a benign public sphere in connection with the state and society (Yan, 2003). Chinese scholar Wang Lusheng (2006) argues that blogs have become a powerful tool for bloggers, as their political speech may influence public issues which are of serious concern and are thus actively discussed in the blogosphere.

Zhao Zhili (2006) notes that blogs consist of news delivery as traditional media always do. With the rapid development of blogs in China, much is known about the popularity of journalistic blogs, a type with increasing prominence in public life and important impact on Chinese news culture. News blogs can be situated within a shorter history of alternatives to established news forms in China, such as discussion forums, online newspapers and online storytelling. They are conducted as online journalism in distinction with traditional media frames (McCoy, 2001). This online journalism is, as Steen Steensen describes:

[O]ften marked by an attempt to establish new normative demands for the practice of journalism rather than building on traditional journalistic skills and craftsmanship.

(2009, p.704)

The discourse of blogs as online journalism in China is organized around the idea of challenging mainstream news culture (Yan, 2003; Wang, 2006). Yan Chunjun (2003) describes that the blogging environment is a challenge to the practices of journalism, in which it will create a new generation of journalistic conventions and attack old Chinese media system. The advantage of news blogs, as some argue, they have reported events faster than newspaper and television (Walker, 2001). They have provided quality journalism in terms of fact-based comments, up-to-the-moment stories and in-depth analyses. Journalistic blogs, as Mark Deuze (2003) suggests, post their opinions on a personal level, though, they are more likely to write for the public than writing to the public.

A number of prominent news-related blogs are produced by professional columnists, editors and journalists, many of their writings insert the critical point of the wide commentary on the essential discourses of journalism and they are not normally emerged through the newsroom editing machine (Lasica, 2002). For instance, Wang Xiaofeng commented on his 'Massage Milk' (http://lydon.ycool.com):

[T] he blog is the tool for recording miscellaneous things, and I found that the blog was more suitable for me to relax myself... Having been a reporter at Lifeweek for several years, I have developed a psychological problem... I get very nervous because our editor-in-chief is difficult to hoodwink... After I started blogging, I have relieved my tense nerves and broadened my thoughts. (3 December 2004) 
Wang also claimed:

One of the characteristics of a blog is that it is completely different from the traditional media... For me, when I write for the Lifeweek, it seems that I am writing for my editor-inchief. But when I write my blog, I am absolutely writing for myself... I have treated the blog as an extension of my work. I write about affairs that I cannot usually publish in the print media... Therefore, I set up a principle in my blog that my posts must be distinct from those which have been published in the Lifeweek magazine. (3 December 2004)

The migration of news and information to an online platform has also disrupted old patterns of reading and changed the relationship between audiences and news providers. The two-way interaction conflicts with a tradition view of professional journalists as producers and readers as consumers, though, the presentation of news content by journalists makes a professional claim to know on behalf of the audience (Matheson, 2004, p. 453-5). Steen Steensen notes that:

A journalist would, for example, perform one aspect of her role in interaction with sources, a different aspect in interaction with the audience and yet another aspect in interaction with in-house marketing personnel. (2009, p. 706)

A popular blogger Lvqiu Luwei, who is a star reporter of Phoenix TV, posts her viewpoints in her 'Rose Garden' (http://www.my1510.cn):

We can see that there is an interaction between traditional media and blogs in China. For instance, some news stories began with tips from bloggers. Though, traditional media outlet is likely to publish news story by means of observing journalistic ethics and standards and deliberatively verify the information, so as to make a fair and balanced presentation, as opposed to taking sides... My experience in blogging is that there is less restrictive requirement as that in traditional media... but the influence of bloggers is greater than traditional media, at some point. (6 December 2006)

Roland Soong is famous for his ESWN (EastSouthWestNorth, http://www.zonaeuropa.com). His blog translates China-related news and offers observations with cross-cultural acumen. 'The information presented on my blog is partial, selective and idiosyncratic,' Soong states. 'A blog is the effort of a single individual and may excel in some small niche subject area or in reporting a suddenly breaking incident' (Cited in Zhou and Wang, 2006).

By these accounts, news blogs are quite distinctive from traditional news report. Journalist blogs abide by a new element of transparency as they practice journalism, and they reshape news material in the text around a new angle (Lasica, 1998). In addition, blogs' hyperlinks allow journalists to extrapolate from the given facts and expand on them for the sake of good stories (Wall, 2004). Furthermore, news blogs have a prominent political influence in society. They constructively, as Zhang Lei and Lou Chengwu (2006) suggest, enhance surveillance of political behavior of officials as well as invitation of discussions on public interests. This in turn can broaden the focus to inquire about the sociopolitical diffusion and development of the blogosphere in China beyond the democratization frame. 


\section{PUBLIC JOURNALISM IN PRACTICE: LIAN YUE'S EIGHTH CONTINENT ON XIAMEN PX PROJECT}

It is worthy noted that the importance of news blogs as a new form of public journalism and this has greatly challenged traditional mainstream media. In the first place, public concerns tend to become the primary focus for Chinese journalists and these concerns turn to drive their critic reporting in their blogs. Second, News blogs encourage independent source of information and independent investigation of the facts to fill the perceived inadequacies from the government and its mainstream media institutions (Zhan and Lou, 2006). In other words, journalistic blogs in China have extended the narrow range of topics and sources featured in mainstream news media outlet and they may possibly negotiate with traditional media with regard to discussions on sensitive political events. Last but not the least, for radical journalists, blogs are not only a means of practicing their profession, as Zhao Zhili argues (2006), but also a purpose of energizing them for public participation.

Starting in March 2007, Southern Metropolis Daily columnist Lian Yue, who is also a Xiamen resident, posted a series of articles on his Lian Yue's Eighth Continent, warning the people of Xiamen that a paraxylene (PX) chemical factory being built in the city could have a disastrous environmental impact and calling on his fellow residents to speak out against this project. On March 29, he wrote in his Lian Yue de Diba Dazhou (Lian Yue's Eighth Continent) (http://www.lianyue.net/blogs/rous):

Now the core of the event is that relevant information has been blocked from Xiamen citizens. Before yesterday's meeting of Xiamen People's Political Consultative Conference, there were members who heard about the PX project and the proposal by Zhao Yufen for the first time from me. That means the cover-up is very successful. So for the time being, the most important thing is anti-censorship. (29 March 2007)

The post was published in What Xiamen People Can Do on his blog.

'[D]on't be afraid', Lian Yue persuades:

This is a project objected to by 105 CPPCC members, among whom there are the most authoritative experts.

- The PX project should be placed at least 100 kilometers away from cities to ensure safety.

- Xiamen people are still deprived of the right to know the danger of the PX project. This is counterevidence that the project is against people's will.

- The project will lead to the recession of Xiamen's economy, the depreciation of properties, and the decrease of visitors. Xiamen people will also be viewed as weak and stupid.

- The project will increase the possibility of getting cancer.

- You don't have to behave very bravely. Just let people beside you know this event, and you will not be held accountable for the death of Xiamen.

(29 March 2007)

This hearing quickly resulted in a subsequent spread of the PX project throughout Xiamen via emails and instant messages. On June 1 and 2 in 2007, in defiance of warnings from local authorities, a thousand Xiamen citizens showed up to walk in protest in front of the city government, along with the theme 'Oppose PX, Protect Xiamen' (see Left picture) and a second banner (see Right picture) reads 'Protect Our Children's Health'. Participants also reported the scene with live transmitted photos and texts (Kennedy, 2007). For instance, the Bullog (http://www.bullogger.com) members posted live updates of informing on what was 
happening minute-by-minute on the ground by the afternoon of July 1, meanwhile, a video of the march had been uploaded to YouTube.

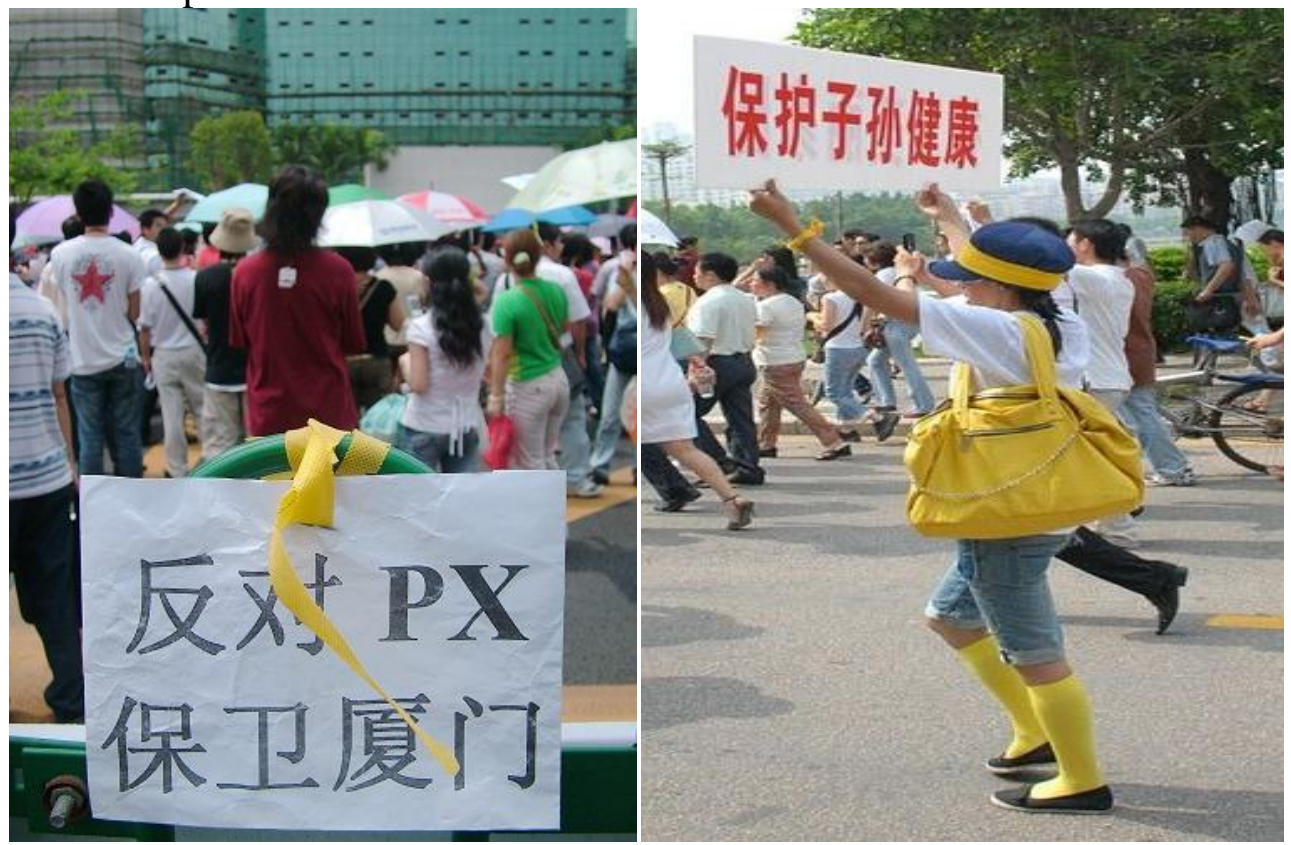

Source: John Kennedy (2007, 1 June) 'China: Liveblogging from Ground Zero'

Available at: http://globalvoicesonline.org/2007/06/01/china-liveblogging-from-ground-zero/

These activities offered chances to hear more reliable selections of opinions on the project. For instance, Xiamen Online launched a poll to measure the public's reaction, with 55,376 of 58,454 votes were cast against the project (Martinsen, 2007).

Under the great pressure of public opinions opposed to the PX project, in mid December 2007, the Xiamen government chose to set up a face-to-face conversation with the city residents. A hundred representatives attended that meeting. Fifty from the People's Congress and Political Consultative Committee, and fifty from residents of Haicang District, where the project is located (Lian, 2007). In terms of their focus on living environment, Haicang residents strongly claimed that they opposed the project and showed their anger in the meeting. The following are reactions from the representatives and Lian Yue recorded these debates in his 'Lian Yue's Eigth Continent':

Number 25 and 28 raised the question of why a beautiful tourist city like Xiamen would want to expand its heavy industry - would the trade-off be worth it? ... Number 33 argued that the PX project was in the flight path of a proposed airport, raising the pos sibility of a plane crash made more deadly by the chemicals released. (14 December 2007)

Lian Yue continues to comment:

But many voices directly questioned on the attitude of the government and the local media.

Number 11 argued that the PX project is the wrong decision for the city government... Number 29 questioned the government on its shut down of its website, and number 31 blamed that the process of discussion on PX Project needs more transparency - 'why has Xiamen media been so quiet?' (14 December 2007)

Lian Yue's exploration on Xiamen event not only encouraged the general public to struggle for their rights, but also pushed official media to face the issue. On December 14 2007, China Daily posted its comment under the title Open Forum Held to Air Views on PX Plant: 
Fifty-two of the 57 speakers at a public forum Thursday opposed the development of a chemical plant in the city of Xiamen, Fujian Province. Participants in the forum were chosen by lottery on Tuesday, under the supervision of the Xiamen notary office, from the 624 people who registered online or by calling a hotline number...A further 42 participants will get the chance to voice their views today... Some of those who opposed the scheme argued that the government should find a way to balance the economic development of the area with environmental concerns. (Cited in Chen and Hu, 14 December 2007)

The same day, The Beijing News ran China Daily's information under the headline Over Half of Xiamen Representatives Oppose Chemistry Project in Haicang:

Recently, people provided rational advices and critical comments on the environment assessment report of Haicang District, via hotline, email and letter, again turned their eyes on Xiamen. Meanwhile, the local government started to solicit opinions from the public and decided to run a ten days' meeting for them to air their views on the PX project... We were noted that the decision ultimately rests with the city government... However, creating an industrial zone would require demolishing a number of houses, relocating residents and conducting strict safety controls over the chemical plant. (14 December 2007)

From reading the two articles we can see that the symbolism of the official media also showed a negative attitude on the PX project. After six months of widespread concern, the Xiamen government had to remove the project from Haicang. Fujian provincial government information office director Zhu Qing explained that the decision was made on the basis on an absolute majority of people against the project (Cited in $\mathrm{Zhu}$ and $\mathrm{Su}, 2007$ ). This is the first time since the public participation process began that the Fujian province and Xiamen city government have listened, respected and followed the 'absolute majority' public opinions. In a sense, the Xiamen government's allowing the demonstrators the right to protest and then taking public opinions into account showed a progressive turn. The year of 2007 was particularly remarkable in this regard.

Lian Yue's blogging on Xiamen PX event is an indication of the new arena that the growing prominence of the blogosphere has opened a new space for public journalism. Jay Rosen described three dimensions of public journalism as 'an argument, a practice, and a movement' (1995, p.22). We start to see a transparency in media report, a new degree of autonomous power for news delivery and public controversy. All these may not remove state control of journalism overnight, though, the political outcome of compromise and negotiation will greatly catalyse China's authoritarian regime towards further political transition.

\section{CONCLUSION}

While blogs approach the public and get support via their dialogue skills, journalists' high level of talent at commenting on societal events, expressing independent thoughts and judgment are particularly more competent than other bloggers. To talk in terms of competence does not imply a priori assessment of the power of journalists. I simply mean here that journalists focus more on their work, thought and responsibility in their blogs. Put it another way, journalists take advantages in terms of strengthening and expanding the goal of transparency as well as offering political views on the process of mass communication (Singer, 2005, p.192-193).

Journalism in China now faces challenges and changes which are sufficiently dramatic to require a redefinition of its role, professional and format. By focusing on Lian Yue's blog, we 
are asserting that shifting news delivery from traditional media to the Internet have changed rules of the game of journalism. What we found in the PX Project, either through Lian Yue's blog contents, or comments from China Daily and The Beijing News that revealed deep social conflicts between Xiamen people and their city government and therefore, criticism behind the conflicts had been radically expressed. Lian Yue and his counterparts criticized the systematic problem within Chinese society, in which Xiamen government's emphasis on economic development over ordinary people's benefits that had resulted in a failure of the government's leadership, and a negative mood of Xiamen residents toward the local officials.

The change means that the need for news repair (Bennett et al., 1985; McCoy, 2001) is the very target. When journalists engage in an effort to access the validity of a news story by linking the issues that the public would be concerned about, to the extent that journalists holding positive attitudes especially in terms of credibility and responsibility (Eksterowicz and Roberts, 2000, p.187), through which journalists attempt to reconfirm the legitimacy and validity of their own model of journalism (Wall, 2004; Singer, 2005), is a manifestation of the broader phenomenon of news repair. If, borrowing Stephen Reese et al.'s viewpoint:

\begin{abstract}
These bloggers, for the most part, simply engage the facts and information carried in news accounts, accepting them at face value and using them to form their own arguments, reinforce views, and challenge opponents. They rarely challenge specific reportorial techniques and larger media structures. We may thus regard them ironically as in some ways preserving and reinforcing professional norms of journalism as they disseminate content generated by traditional reporting practices. (2007, p.257)
\end{abstract}

On the other side, Chinese journalistic blogs, at a more individualistic level, act as 'voices of people' (Pugsly and Gao, 2007, p.452), recognized for their contributions in nationwide contests in pursuit of helping the process of public life determine the outcomes (Zhang and Lou, 2006) and thus solving public issues. 'They are concerned more with the public interest and their professional values instead of political safety' (Tong, 2009, p.608). This shift has triggered the rise of new repertoires of professional practices and of new generation of political journalists. And this new generation of the political journalist is, as Eric Neveu (2006, p.38) describes, making journalism 'the medium of expression of a bottom-up political agenda.'

All these may reshape the journalistic profession and the cultural construction of news. In fact, the impact of Lian Yue's blog recognized the value of the blogosphere in opening up a wider space for journalism. Given the tight political control of the mainstream media, there is indeed a tendency among Chinese journalists to see or perhaps wish for blogs as an alternative transparent media. In the case of Xiamen PX project, for example, there seems possible for journalists to enjoy more freedom of political speech in the blogosphere, and it is not difficult to imagine the same enthusiasm for media critique and the public concerns for a democratic life being focused internally.

Thus, the concept of blogosphere recalls Habermas's (1991) idea of the public sphere where public opinion and public communication emerge. In this sense, the political value of news blogs in China is not only presented by radical journalists, but also by the cyberspace public discussions on political events and public issues (Hu, 2006). In other words, blogs influence journalism (Matheson, 2004; Singer, 2005) and on the rise of public journalism (Deuze, 2003) as a way of involving the audience in the practice of journalism. What remarkable in the anti-PX case is that the conflicts of both sides, either Xiamen residents or local government, entered China's public sphere and influenced policy. Additionally, news blogs 
ought to be a mediated space, as Wang Lusheng (2006) suggests, which allows journalists to provide breaking news, in connection with their audiences through the range of sources and opinions being broadly permitted and expressed on this public forum. This in turn raises an expectation of reconstituting spaces for public deliberation, and new conditions for freedom of expression and information in ways difficult to control in future.

\section{REFERENCES}

Bennett, W. Lance, Gressett, Lynne A. \& Haltom, William. (1985) 'Repairing the News: A Case Study of the News Paradigm' [Electronic version]. Journal of Communication, 35/2: $50-68$.

Calhoun, C. (1992) 'Introduction: Habermas and the Public Sphere'. In: C. Calhoun ed. Habermas and the Public Sphere. Cambridge, M.A.: The MIT Press. pp.1-50.

CASS (2008, 3 January) Shehui Lanpishu (Annual Blue Book). Social Sciences Academic Press (China).

Chan, J. M. (2003) Administrative Boundaries and Media Marketization: A Comparative Analysis of the Newspaper, TV and Internet Markets in China. In Chin-Chuan L. ed., Chinese Media, Global Contexts. London: Routledge. pp. 159-176.

Chen, H. L. \& Chan, J. M. (1998) Bird-Caged Press Freedom in China. In Joseph Y. S. Cheng ed., China in the Post-Deng Era (pp. 645-668). Hong Kong: The Chinese University Press.

Chen, J. \& Hu, M. D. (2007, December 14) Open Forum Held to Air Views on PX Plant. Available at: http://www.chinadaily.com.cn/china/2007-12/14/content_6320406.htm. [Accessed: 2 October 2009].

CNNIC (2009) 2008-2009 Zhongguo Boke Shichang ji Boke Xingwei Yanjiu Baogao (20082009 Survey Report on China Weblog Market). Available at: http://research.cnnic.cn/html/1247815387d1066.html [Accessed: 12 September 2009].

Deuze, M. (2003) 'The Web and its Journalisms: Considering the Consequences of Different Types of Newsmedia Online' [Electronic version]. New Media \& Society, 5/2: 203-220.

Eksterouwicz, A. J. \& Roberts, R. N. (2000) 'Epilogue: Public Journalism and the Future'. In: Anthony J. E. and Robert N. R. eds., Forward by Jay R. Public Journalism and Political Knowledge (pp. 185-187). Rowman \& Littlefield Publishers, Inc.

Habermas, J. (1991) The Structural Transformation of the Public Sphere: An Inquiry into a Category of Bourgeois Society. Translated by Thomas, B. with the Assistance of Frederick, L. Cambridge, M.A.: The MIT Press.

He, Z. \& Zhu, J. H. (2002) The Ecology of Online Newspapers: The Case of China [Electronic version]. Media Culture Society, 24/1: 121-137. 
Hu, C. Y. (2006) Boke Xianzhuang yu Jidai Yanjiu de Wenti (The Study of Blog on Its Current Situation and Issues). Journal of Shanghai Journalism Review, 3: 13-15.

Huang, C. J. (2007) 'Editorial: From Control to Negotiation: Chinese Media in the 2000s' [Electronic version]. International Communication Gazette, 69/5: 2-412.

Kennedy, J. (2007, 1 June) 'China: Liveblogging from Ground Zero'. Available at: http://globalvoicesonline.org/2007/06/01/china-liveblogging-from-ground-zero/ [Accessed: 2 October 2009].

Lasica, J. D. (1998, 1 April) Slow Down and Make Sure it is Right. Available at: http://www.ajr.org/Article.asp?id=1790 [Accessed: 18 September 2009].

Lasica, J. D. (2001, 2 August).'The Promise of the Daily Me: From My News to Digital Butlers: An In-depth Look at the Different Flavors of Personalization'. Available at: http://www.jdlasica.com/2001/08/02/the-promise-of-the-daily-me/ [Accessed: 18 September 2009].

Lian, Y. (2007, 29 March) Xiamen Renmin Zhemeban! (What Xiamen People Can Do). Available at: http://www.lianyue.net/blogs/rous/archives/37332.aspx [Accessed: 2 October 2009].

Lian, Y. (2007, 14 December) 87.5\% Daibiao Fandui PX (87.5\% of the Representatives Oppose the PX). Available at: http://www.lianyue.net/blogs/rosu/archives/118196.aspx [2 October 2009].

Lvqiu, L. W. (2006, December 6) Boke de Zhongguo Tese (Chinese Blogs Have Unique Chinese Characteristics). Available at: http://www.my1510.cn/article.php?id=d3e30d5e78c15027 [Accessed 2 October 2009].

Ma, E. K-W. (2000) 'Rethinking Media Studies: The Case of China'. In: James C. \& MyungJin P. eds., De-Westernizing Media Studies. New York: Routledge. pp. 21-34.

Massey, Brian L. \& Luo, Wei. (2005) 'Chinese Newspapers and Market Theories of Web Journalism’ [Electronic version]. Gazette, 67/4: 359-371.

Matheson, D. (2004) Weblogs and the Epistemology of the News: Some Trends in Online Journalism [Electronic version]. New Media Society, 6/4: 443-468.

Martinsen, J. (2007) 'Citizens Air Opinions on the Xiamen PX Project'. Available at: http://www.danwei.org/environmental_problems/citizens_opinions_on_the_xiame.php [Accessed: 2 October 2009].

Mayhew, L. H. (1997) The New Public: Professional Communication and the Means of Social Influence. Cambridge, U.K.: Cambridge University Press.

McCoy, M. E. (2001) 'Dark Alliance: News Repair and Institutional Authority in the Age of the Internet'. Journal of Communication, 51/1: 164-193.

McGuigan, J. (1996) Culture and the Public Sphere. New York: Routledge. 
McKee, A. (2005) The Public Sphere: An Introduction. Cambridge, U.K.: Cambridge University Press.

Negt, O. \& Kluge, A. (1993) Public Sphere and Experience: Towards an Analysis of the Bourgeois and Proletarian Public Sphere. Minneapolis: University of Minnesota Press.

Neveu, E. (2006) Four Generations of Political Journalism. In Raymond K. \& Eric N. eds., Political Journalism: New Challenges, New Practices. New York: Routledge. pp. 22-44.

Pan, Z. D. (2000) 'Spatial Configuration in Institutional Change: A Case of China's Journalism' [Electronic version]. Journalism, 1/3: 253-281.

Pugsley, P. C. \& Gao, J. (2007) 'Emerging Powers of Influence: The Rise of the Anchor in Chinese Television' [Electronic version]. The International Communication Gazette, 69/5: 456-466.

Reese, S. D., Rutigliano, L., Hyun, K. \& Jeong, J. (2007) 'Mapping the Blogosphere: Professional and Citizen-based Media in the Global News Arena' [Electronic version]. Journalism, 8/3: 235-261.

Rheingold, H. (2000) The Virtual Community: Homesteading on the Electronic Frontier. Cambridge, M.A.: The MIT Press.

Rosen, J. (1999) 'The Action of the Idea: Public Journalism in Built Form'. In: Theodore, L. G. ed., Foreword by Cole, C. C. (pp. 21-48). The Idea of Public Journalism. Guilford Press.

Singer, J. B. (2005) 'The Political J-Blogger: 'Normalizing a New Media Form of Fit Old Forms and Practices' [Electronic version]. Journalism, 6/2: 173-198.

Steensen, S. (2009) 'The Shaping of a Feature Online Journalist' [Electronic version]. Journalism, 10/5: 702-718.

Tai, Z. X. and Sun, T. (2007) 'Media Dependencies in a Changing Media Environment: The Case of the 2003 SARS Epidemic in China' [Electronic version]. New Media Society, 9/6: 987-1009.

Thebeijingnews (2007, 14 December) Yu Ban Xiamen Shimin Daibiao Fandui Haicang Gao Huagong (Over Half of Xiamen Representatives Oppose Chemistry Project in Haicang). Available at: http://www.thebeijingnews.com/news/guonei/2007/12-14/021@090051.htm [Accessed: 2 October 2009].

Tong, J. R. (2007) 'Guerrilia and Tactics of Investigative Journalists in China' [Electronic version]. Journalism, 8/5: 530-535.

Tong, J. R. (2009) 'Press Self-Censorship in China: A Case Study in the Transformation of Discourse' [Electronic version]. Discourse \& Society, 20/5: 593-612.

Walker, R. (2001, 7 March) 'The News According to Blogs'Available at: http://www.slate.com/id/102057/ [Accessed:18 September 2009]. 
Wall, M. (2004) 'Blogs as Black Market Journalism: A New Paradigm for News'. Available at: http://bcis.pacificu.edu/journal/2004/02/wall.php [Accessed: 3 October 2009].

Wang, L S. (2006) Boke dui Shehui Wenhua jiqi Chuanbo Moshi de Yingxiang (The Impact of Blogs on Society and Culture and its Model of Communication). Journal of Guangdong Education Institute, 2/4: 72-76.

Wang, X. F. (2004, 3 December) Guanyu Wo Boke de Mingzi (About the Name of My Blog Site). Available at: http://lydon.ycool.com/index74.html [Accessed: 25 September 2009].

Wang, X. F. (2005, 9 November) Jizhe Jie (The Journalist's Disaster). Available at: http://lydon.ycool.com/post.950736.html [Accessed: 25 September 2009].

Xie, Y. M. (2007) Ni Ye Keyi Chengwei Boke Gaoshou (You May Also Become a Popular Blogger). China Textile \& Apparel Press.

Yan, C. J. (2003) Boke he Geren Meiti Shidai (Bloggers and Personal Media Era). Journal of Fujian Tribune (The Humanities \& Social Science Bimonthly), 3: 28-32.

Yang, G. B. (2003) The Internet and the Rise of the Transnational Chinese Cultural Sphere [Electronic version]. Media Culture Society, 25/4: 469-490.

Yang, Y. R. (2007) Jiaodian Fangtan Xinwen Pinglun Yuyan Jiexi (A Journalistic Analysis on Focus). Press Circles, 2: 97.

Zaret, D. (1992) 'Religion, Science, and Printing in the Public Spheres in SeventeenthCentury England'. In Craig, C. ed., Habermas and the Public Sphere. Cambridge, M.A.: The MIT Press. pp. 212-235.

Zhang, L. and Lou, C. W. (2006) 'Zhengzhi Boke de Fazhan Xianzhuang jiqi Weilai Qushi' (An Analysis of Current Status and Trends of Political Blogs). Social Sciences Journal of Zhongshan University, 46/4: 99-102.

Zhang, X. G. (1993) 'The Market Versus the State: The Chinese Press since Tiananmen'. Journal of International Affairs, 47/1: 195-221.

Zhao, Z. L. (2006) 'Boke Leng yu Re de Sikao: dui Xinwen Boke de Chuanboxue Jiedu' (The Popularity and Unpopularity of the Blog: Understanding News Blog in the Realm of Communication Studies). Social Science Journal of Nanjing University of Posts and Telecommunications, 8/2: 23-26.

Zheng, Y. N. \& Wu, G. G. (2005) 'Information Technology, Public Space and Collective Action in China' [Electronic version]. Comparative Political Studies, 38/5: 507-536.

Zhou, R. \&Wang, Z. Q. (2006, 31 May) 'New Forms of New Media Are in Vogue'. China Daily [Electronic version]. Available at: http://www.chinadaily.com.cn/cndy/2006-

05/31/content_604442.htm [Accessed: 13 October 2009]. 
Zhu, H. J. \& Su, Y. T. (2007, 19 December) Xiamen PX Xiangmu Qianzhi Zaiwang: Minyi yu Zhihui Gaibian Xiamen Quyu Duoying (Xiamen Calls an Abrupt Halt to the PX Project to Deal with the Public Crisis). Available at: http://www.infzm.com/content/9650 [Accessed: 2 October 2009].

Zittrain, J. \& Edelman, B. (2003) 'Empirical Analysis of Internet Filtering in China'. Available at: http://cyber.law.harvard.edu/filtering/china/ [Accessed: 15 September 2009]. 